\title{
Effect of Subcision and Microneedling in the Treatment of Atrophic Acne Scars in Patients: A Case Series
}

\section{Rai $\mathbf{T}^{1}$, Tandon $\mathbf{M}^{2}$}

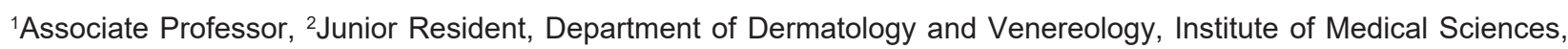
Banaras Hindu University, Varanasi, India

\begin{abstract}
Background: Acne vulgaris is a common condition with a prevalence of over $90 \%$ among adolescents and post- acne scarring is a well known sequelae. Different types of scars (ice pick, boxcar, and rolling scars) warrant a customized approach of treatment for each type. We propose a novel treatment of atrophic acne scars using combination of subcision and microneedling.

Materials and Methods: Ten consecutive patients of skin types III - IV with moderate and severe facial acne scarring received three sequential subcision and micro-needling treatments after informed consent over a period of three months with an interval of 4 weeks between each session. Goodman and Baron's qualitative and quantitative acne scar grading systems along with side by side comparison of pre-operative and post-operative photographs were used for assessment at the end of three sessions of the combination procedure.

Results: Estimation of improvement with Goodman and Baron's Global qualitative acne scarring system, we found good results in patients with Grades 3 and 4 acne scars. Out of 7 patients with grade 4 scars, 29\% showed improvement by 2 grades and 71\% showed improvement by 1 grade and all the 3 patients with grade 3 scars showed improvement by 1 grade. Quantitative assessment showed 30\% patients had minimal improvement, 50\% had moderate improvement and $20 \%$ had good improvement in scars. Adverse effects were transient pain, erythema and oedema.

Conclusion: Subcision and microneedling are simple and inexpensive office procedures which in combination are well tolerated and are efficacious in treatment of moderate and severe acne scars.

Key words: Acne Vulgaris; Cicatrix; Needles
\end{abstract}

\section{Introduction}

A cne vulgaris is a common condition with a prevalence of over $90 \%$ among adolescents, ${ }^{1}$ and often causes an unfortunate and permanent complication of scarring that results from an altered wound healing response to cutaneous inflammation. Post-acne scarring has a significant negative impact on quality of life of young patients and is a challenging condition for dermatologists with no easy and definitive solution. For choosing the appropriate intervention, assessment of the severity of scarring is necessary. The severity assessment is done by classification of the scars. They have been broadly classified into three different types: atrophic, hypertrophic, or keloidal. Hypertrophic and keloid scars are the result of net

Funding: No

Conflict of Interest: No

Address of Correspondence

Dr. Megha Tandon

Banaras Hindu University, India

E-mail: meghatan1993@gmail.com gain of collagen during the healing process, while scars characterized by destruction of collagen in the dermis are atrophic.

Atrophic acne scars are the most common type and are further classified as ice -pick (V-shaped), rolling (W-shaped) and boxcar (U-shaped). ${ }^{2,3}$ The exact prevalence of each scar type is hard to calculate but some estimations report that within atrophic scars, the ice pick type represents $60-70 \%$, boxcar $20-30 \%$, and

Submitted: $2^{\text {nd }}$ September 2020

Accepted: $30^{\text {th }}$ December 2021

Published: $20^{\text {th }}$ February 2021

\section{How to cite this article}

Rai T, Tandon M. Effect of Subcision and Microneedling in the Treatment of Atrophic Acne Scars in Ten Patients: A Case Series. Nepal Journal of Dermatology, Venereology \& Leprology 2021;19(1):74-80. https://doi.org/10.3126/njdvl.v19i1.30974 .

\section{(c) (i)}

Licensed under CC BY 4.0 International License which permits use, distribution and reproduction in any medium, provided the original work is properly cited. 
rolling scars $15-25 \%$.It is common for patients to have more than one type of scar.

For the treatment of atrophic acne scars over face, several approaches have been developed. Medical management includes the use of topical and oral retinoids, while surgical methods include punch elevation, punch excision, subcision and elliptical excision. Different procedures include chemical peels, percutaneous collagen induction by dermabrasion and microneedling, dermal grafting, focal treatment with trichloroacetic acid, fillers, fat transfer, various ablative and nonablative lasers, and light energies. ${ }^{4}$ Microneedling is a technique that is a part of percutaneous collagen induction $(\mathrm{PCl}$ ) therapy and involves puncturing the skin multiple times using needles. ${ }^{5}$ It is thought that needles break collagen bundles in the superficial layer of the dermis that are responsible for scars with subsequent induction of more collagen immediately under the epidermis. ${ }^{6}$ Microneedling primarily targets superficial boxcar scars. Subcision (subcutaneous incisionless surgery) is another safe technique in which a needle is inserted percutaneously adjacent to the scar to manipulate and release fibrous tissue, which pulls the scar down. ${ }^{7}$ It primarily targets rolling type of atrophic scars. The efficacy and safety of combination of subcision and microneedling procedures in moderate to severe atrophic acne scars was evaluated.

\section{Materials and Methods}

A retrospective photographic analysis of 10 consecutive patients with Global Acne Scarring Classification grades 2 to 4 treated with a combination of subcision and microneedling after informed consent for moderate to severe facial atrophic acne scarring was done at the Department of Dermatology and Venereology in a tertiary care teaching hospital between January 2019 and March 2019. The age of the patients ranged from 16 to 32 years with a mean age of 22 years and had Fitzpatrick skin type III - IV. Patients were excluded if they were pregnant, lactating, had active acne, any active infection, keloidal tendency, undergone any surgery or procedure for for acne scars in previous three months. Ten consecutive patients ( 5 males and 5 females) met the inclusion criteria.

Patients had undergone three sessions of subcision and microneedling with an interval of 4 weeks in between each session, since the time for collagen remodelling lasts around 4-6 weeks. The procedure area was thoroughly cleaned with saline and povidone iodine and anaesthetised with thick coating of topical anaesthetic cream (lidocaine $2.5 \%$ and prilocaine $2.5 \%$ ) left for 60 minutes under occlusion. Subcision was performed using 18-gauze, tribeveled, hypodermic needle in which the needle was inserted into the deep dermis, parallel to the skin surface with bevel upwards and then moved back and forth under the scars. Microneedling was performed using dermaroller with 192 needles and $1.5 \mathrm{~mm}$ needle size. It was rolled on the scarred skin in eight directions (horizontal, to the right, to the left, vertical, up, down, and in both diagonal directions) applying minimal pressure and at the same time affected area was stretched in a perpendicular direction to the dermaroller movement so that the base of the scars could also be reached.The presence of uniform bleeding points over the scarred area was the end point for any treatment session. All the patients were instructed to apply topical antibiotic (fusidic acid) for 24 hours and were advised oral antibiotic for 7 days to guard against secondary infection and oral non steroidal anti-inflammatory drugs (NSAIDs) for 2 to 5 days for pain relief. Patients were also advised to apply sunscreen over the entire face every morning and avoid sun exposure. Adverse effects that occurred post-treatment including erythema, swelling, post inflammatory hyper pigmentation, and any interference with daily activities were noted.

The response was evaluated clinically by before and after photographs and pre-treatment grading of scars was compared with final grading using the global acne scarring classification of Goodman and Baron [Tables 1 and $2 \mathrm{a}$ and $\mathrm{b}]^{8,9}$

\section{Results}

Out of 10 patients, 5 (50\%) were women and 5 (50\%) were men, with an age range of 16 to 32 years and mean age of 22 years. Acne scar duration varied from less than 1 year to more than 10 years. Most patients had mixed types of atrophic acne scars, including ice pick, boxcar and rolling scars. According to Goodman and Baron acne scar grading scale, 7 patients presented with grade 4 scars and 3 patients presented with grade 3 scars on both sides of the face. At the end of 1 month after last session, qualitative assessment by Goodman and Baron's Global acne scarring system showed that out of 7 patients with grade 4 acne scars, 2 patients (29\%) showed reduction by 2 grades (Figures 1 and 2 ) and 5 patients (71\%) by 1 grade (Figure 3 ). All the 3 patients with grade 3 acne scars showed reduction by 1 grade (Figure 4) (Tables 3 and 4). Estimation of improvement with Goodman and Baron's Global quantitative acne scarring system showed that 3 patients $(30 \%)$ had minimal improvement $(p=0.22), 5$ patients $(50 \%)$ had moderate improvement $(p=0.005)$ and 2 patients $(20 \%)$ had good improvement $(p=$ 
0.016). The improvement in patients with Grade 4 scars at baseline was found to be statistically significant. The study showed good response to treatment for rolling and boxcar scar types with no failure rate (Table 5). The combination treatment was well tolerated. All patients had reported mild erythema and oedema for 1 to 2 days, with no interference in daily routines. None of the patients had complaints of post- inflammatory hyperpigmentation.

Table 1: Goodman and Baron's qualitative acne scar grading system ${ }^{8}$

\begin{tabular}{|c|l|l|l|}
\hline Grade & Level of disease & Characteristics & Examples \\
\hline 1 & Macular disease & $\begin{array}{l}\text { Erythematous, hyper- or hypo pigmented flat marks } \\
\text { visible to patient or observer irrespective of distance }\end{array}$ & $\begin{array}{l}\text { Erythematous, hyper- or } \\
\text { hypo pigmented flat marks }\end{array}$ \\
\hline 2 & Mild disease & $\begin{array}{l}\text { Mild atrophy or hypertrophy that may not be obvious at } \\
\text { social distances of } 50 \text { cm or greater and may be covered } \\
\text { adequately by make-up or the normal shadow of shaved } \\
\text { beard hair in males or normal body hair if extrafacial }\end{array}$ & $\begin{array}{l}\text { Mild rolling, small soft } \\
\text { papular }\end{array}$ \\
\hline 3 & $\begin{array}{l}\text { Moderate } \\
\text { disease }\end{array}$ & $\begin{array}{l}\text { Moderate atrophic or hypertrophic scarring that is } \\
\text { obvious at social distances of } 50 \text { cm or greater and is not } \\
\text { covered adequately by make-up or the normal shadow } \\
\text { of shaved beard hair but is still able to be flattened by } \\
\text { manual stretching of the skin }\end{array}$ & $\begin{array}{l}\text { More significant rolling, } \\
\text { shallow "boxcar,"mild to } \\
\text { moderate hypertrophic or } \\
\text { opular scars }\end{array}$ \\
\hline 4 & Severe disease & $\begin{array}{l}\text { Severe atrophic or hypertrophic scarring that is obvious } \\
\text { at social distances of 50 cm or greater and is not covered } \\
\text { adequately by make-up or the normal shadow of shaved } \\
\text { beard hair in males or body hair (if extrafacial) and is not } \\
\text { able to be flattened by manual stretching of the skin }\end{array}$ & $\begin{array}{l}\text { Punched out aerophic (deep } \\
\text { "boxcar"), "ice pick," bridges } \\
\text { and tunnels, gross atrophy, } \\
\text { dystrophic scars, significant } \\
\text { hypertrophy or keloid }\end{array}$ \\
\hline
\end{tabular}

Table 2: (a) Goodman and Baron's quantitative acne scar grading system 9

\begin{tabular}{|c|c|c|c|}
\hline Grade or Type & No of lesions (1-10) & No of lesions (11-20) & No of lesions (>20) \\
\hline $\begin{array}{l}\text { Milder scarring (1 point each) } \\
\text { Macular erythematous pigmented } \\
\text { Mildly atrophic, dish-like } \\
\text { Moderate scarring ( } 2 \text { points each) } \\
\text { Moderately atrophic, dish-like } \\
\text { Punched out with shallow bases, small scars (<5 } \\
\text { mm) } \\
\text { Shallow but broad atrophic areas } \\
\text { Severe scarring ( } 3 \text { points each) } \\
\text { Punched out with deep but normal bases, small } \\
\text { scars (<5 mm) } \\
\text { Punched out with deep but abnormal bases, } \\
\text { small scars (<5 mm) } \\
\text { Linear or troughed dermal scarring } \\
\text { Deep, broad atrophic areas } \\
\text { Hyperplastic } \\
\text { Papular scars } \\
\text { Keloidal/ Hypertrophic scars }\end{array}$ & $\begin{array}{c}2 \text { points } \\
\text { Area }<5 \mathrm{~mm} \\
6 \text { points }\end{array}$ & $\begin{array}{c}4 \text { points } \\
\text { Area } 5-20 \mathrm{~mm}^{2} \\
12 \text { points }\end{array}$ & $\begin{array}{c}6 \text { points } \\
\text { Area }>20 \mathrm{~mm}^{2} \\
18 \text { points }\end{array}$ \\
\hline
\end{tabular}

Table 2: (b) Assessment of improvement using Goodman and Baron's quantitative acne scar grading system

\begin{tabular}{|c|l|}
\hline Grades & Improvement status \\
\hline $0-5$ & Minimal reduction in GSGS scores \\
$5-10$ & Moderate reduction in GSGS scores \\
$10-15$ & Good reduction in GSGS scores \\
$>15$ & Very good reduction in GSGS scores \\
\hline
\end{tabular}


Table 3: Goodman and Baron's qualitative and quantitative global acne scar scores of 10 patients at baseline and 1 month after the last session of treatment

\begin{tabular}{|c|c|c|c|c|}
\hline Patient & QUALITATIVE SCORE & & QUANTITATIVE SCORE & \\
\hline & BASELINE & 4 MONTHS & BASELINE & 4 MONTHS \\
\hline 1 & 4 & 2 & 18 & 7 \\
\hline 2 & 4 & 3 & 15 & 9 \\
\hline 3 & 4 & 2 & 20 & 14 \\
\hline 4 & 4 & 3 & 20 & 9 \\
\hline 5 & 4 & 3 & 15 & 11 \\
\hline 6 & 3 & 2 & 14 & 9 \\
\hline 7 & 3 & 2 & 12 & 9 \\
\hline 8 & 4 & 3 & 15 & 5 \\
\hline 9 & 3 & 2 & 9 & 13 \\
\hline
\end{tabular}

Table 4: Improvement in Goodman and Baron's qualitative scar grading post treatment in patients with Grade 3 and Grade 4 scars

\begin{tabular}{|c|c|c|c|c|c|}
\hline $\begin{array}{c}\text { Previous to } \\
\text { treatment } \\
\text { grade of acne } \\
\text { scar }\end{array}$ & No of patients & $\begin{array}{c}\text { Post-treatment } \\
\text { reduction of } \\
\text { scars by 3 } \\
\text { grades(\%) }\end{array}$ & $\begin{array}{c}\text { Post-treatment } \\
\text { reduction of } \\
\text { scars by 2 } \\
\text { grades(\%) }\end{array}$ & $\begin{array}{c}\text { Post-treatment } \\
\text { reduction of } \\
\text { scars by 1 } \\
\text { grade(\%) }\end{array}$ & $\begin{array}{c}\text { No post-treatment } \\
\text { reduction of scars(\%) }\end{array}$ \\
\hline Grade 3 & 3 & $0(0)$ & $0(0)$ & $3(100 \%)$ & $0(0)$ \\
\hline Grade 4 & 7 & $0(0)$ & $2(29 \%)$ & $5(71 \%)$ & $0(0)$ \\
\hline
\end{tabular}

Table 5: Improvement in Goodman and Baron's quantitative scar grading after complete treatment

\begin{tabular}{|l|c|}
\hline Improvement status in GSCS scores & No of patients (\%) \\
\hline Minimal reduction & $3(30 \%)$ \\
\hline Moderate reduction & $5(50 \%)$ \\
\hline Good reduction & $2(20 \%)$ \\
\hline Very good reduction & $0(0)$ \\
\hline
\end{tabular}
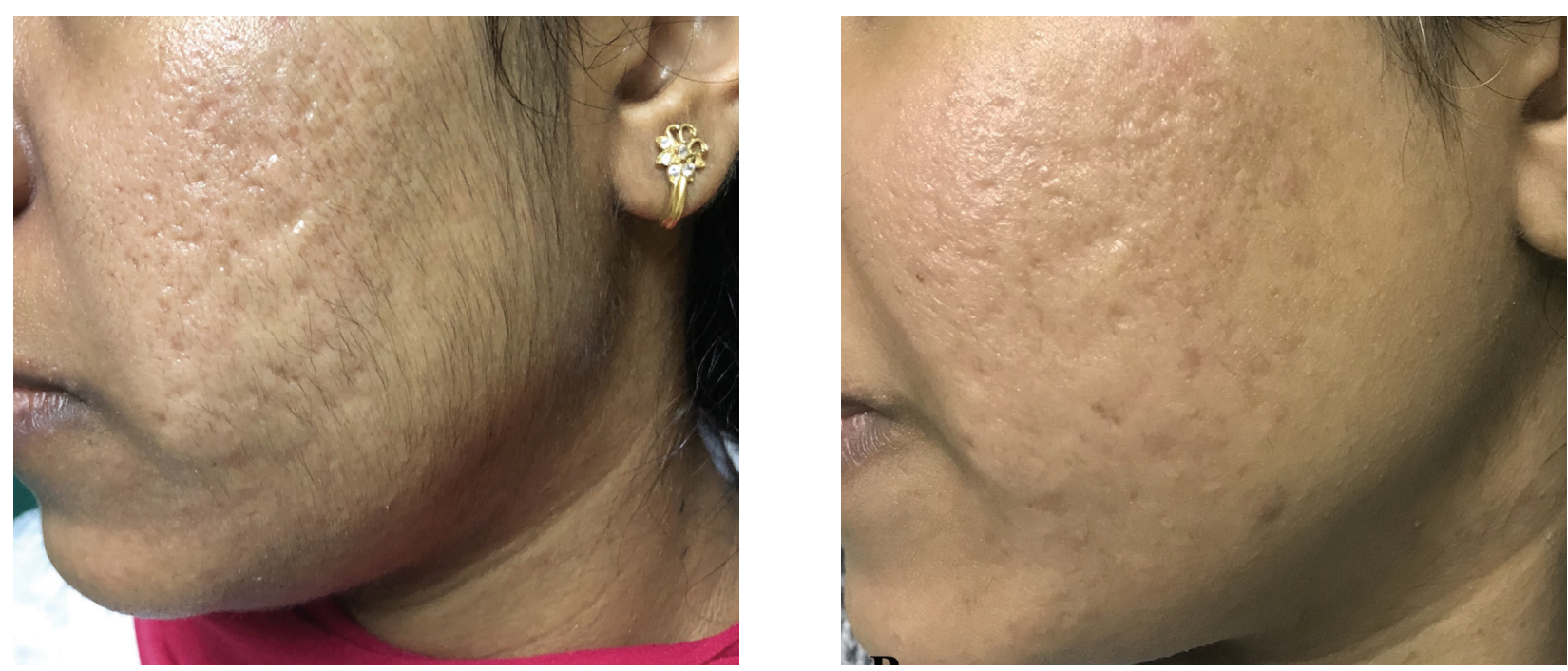

Figure 1: A patient with skin type IV with Grade 4 rolling and boxcar scars- A) before treatment; B) improvement to Grade 2 after 3 sessions of subcision and microneedling 

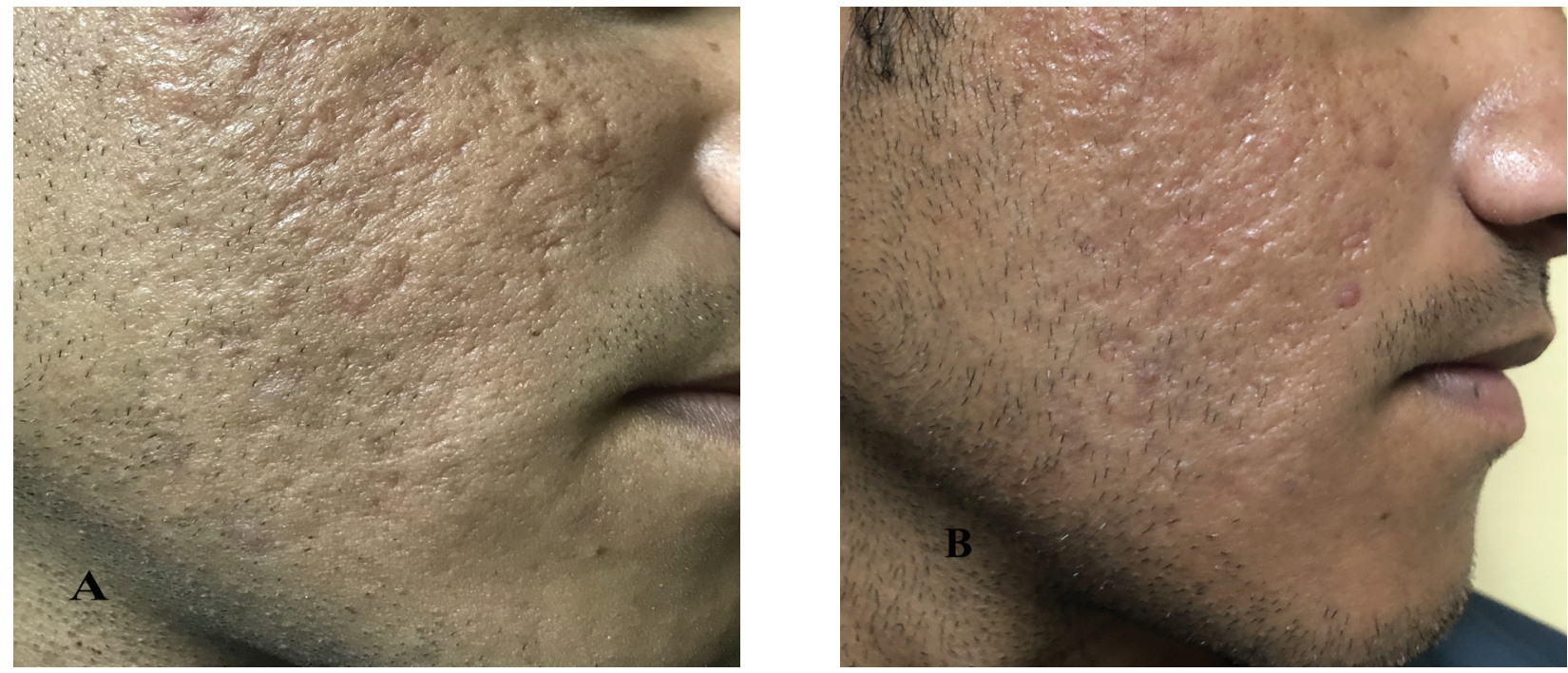

Figure 2: A patient with a mix of rolling, boxcar and ice-pick scars (Grade 4)- A) before treatment B) improvement to Grade 2 after treatment
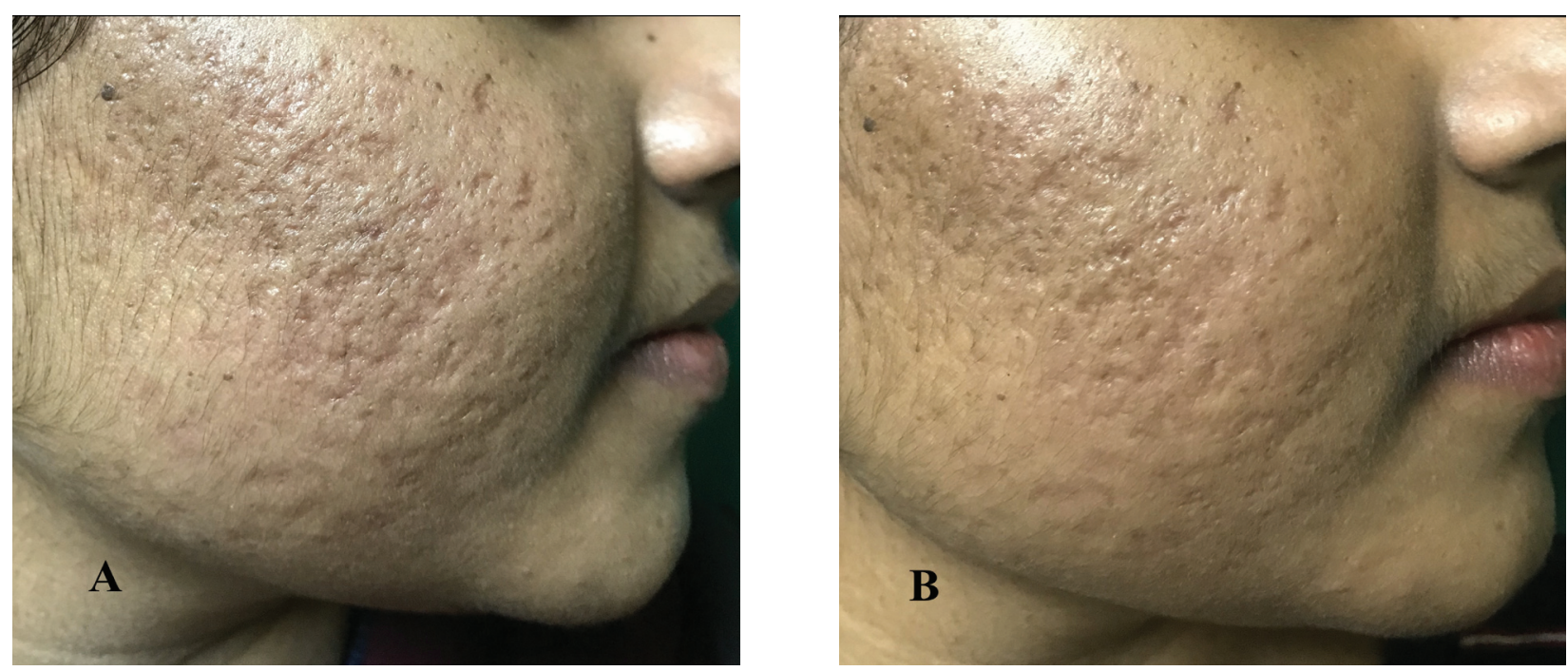

Figure 3: A patient with skin type IV with Grade 4 rolling and boxcar scars- A) before treatment; B) improvement to Grade 3 after 3 sessions of subcision and microneedling
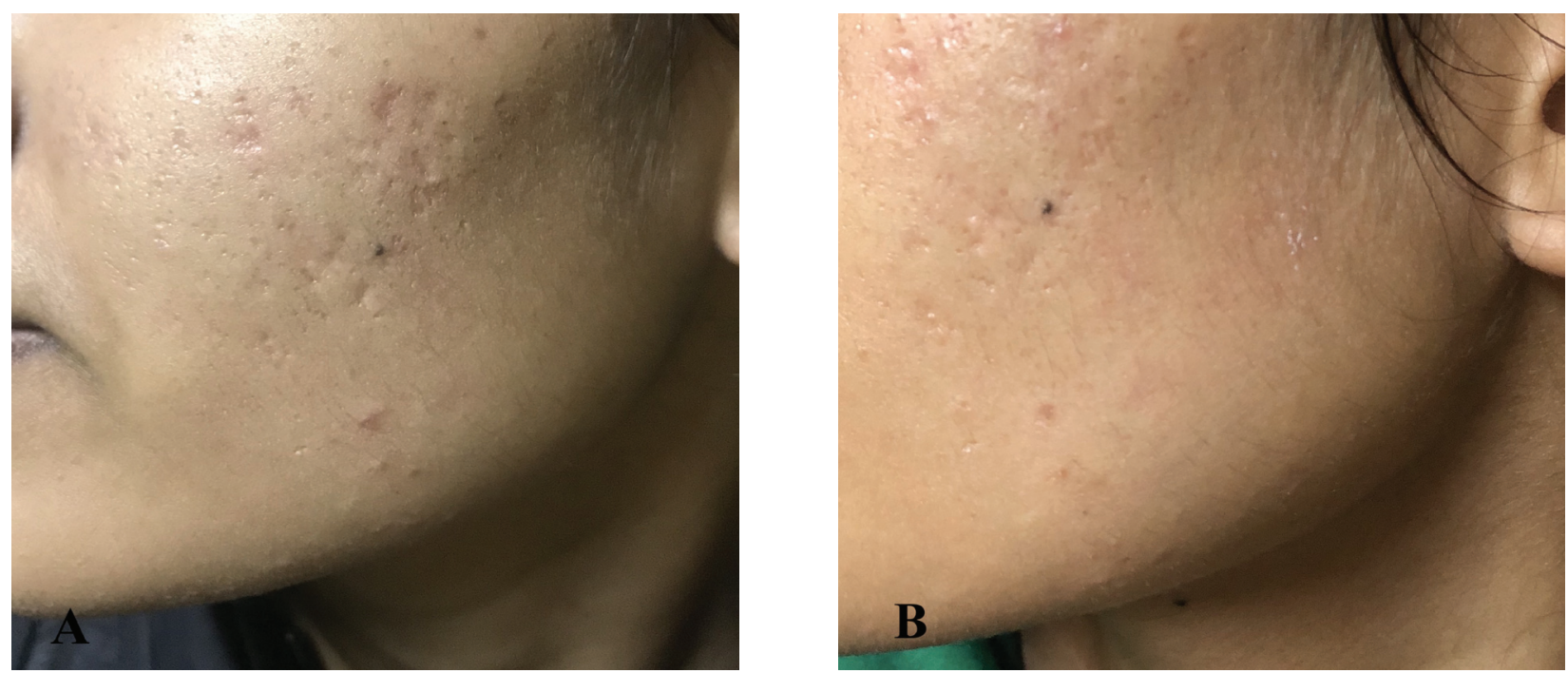

Figure 4: A patient with Grade 3 (ice pick and boxcar scars)- A) before treatment; B) improvement to Grade 2 after treatment 


\section{Discussion}

Microneedling (collagen induction therapy) utilizes tiny needles to puncture the skin multiple times, creating micro-clefts that penetrate into the dermis. The trauma in the dermis initiates wound healing and growth factor release, leading to collagen production and deposition in the upper dermis. ${ }^{10}$ Skin needling renders facial skin smoother and improves rolling acne scars. ${ }^{10}$ Different studies have emphasized the efficacy of micro needling monotherapy in the treatment of acne scars and have shown improvement of at least 1 grade in more than 90 percent of subjects. ${ }^{11-13}$ Melanocyte number is not altered, which justifies the use of microneedling in Fitzpatrick Skin Types III to $\mathrm{V}^{14} \mathrm{~A}$ combination of microneedling with plateletrich plasma has been found to be more effective than microneedling alone in treating acne scars. ${ }^{15-17}$ Significant improvement in acne scars and skin texture has been shown with a combined sequential treatment of microneedling and glycol acid peel. ${ }^{14,18}$

Subcision (subcutaneous incisionless surgery) is a non-operative technique that involves a needle being inserted percutaneously to release fibrotic scar bands in the dermis and subcutaneous tissue, similar to a "mini-scalpel". This approach results in a tethered scar being "released" and allows neocollagenesis to take place beneath the scar, helping to lift and smooth the surface contour. ${ }^{19}$ Deeper, wider, and more noticeable rolling scars improve more dramatically after subcision than do scars that were initially small or shallow, and

\section{References}

1. Ghodsi SZ, Orawa H, Zouboulis CC. Prevalence, severity, and severity risk factors of acne in high school pupils: a community-based study. J Invest Dermatol 2009;129(9):2136-2141. https://doi. org/10.1038/jid.2009.47

2. Jacob $\mathrm{Cl}$, Dover JS, Kaminer MS. Acne scarring: A classification system and review of treatment options. J Am Acad Dermatol 2001;45:109-17. https://doi.org/10.1067/mjd.2001.113451

3. Dreno B, Khammari A, Orain N, Noray C, MurialKieny $C$, Mury $S$, et al . ECCA grading scale: An original validated acne scar grading scale for clinical practice in dermatology. Dermatology 2007;214:46-51. https://doi.org/10.1067/ mjd.2001.113451

4. Rivera AE. Acne scarring: a review and current treatment modalities. J Am Acad Dermatol boxcar scars improve much less than rolling scars. ${ }^{20}$ Subcision has been found to be effective alone as well as in combination with fractional carbon dioxide laser, micro needling, platelet rich plasma and fractionated micro needling radio frequency in various studies. ${ }^{19-25}$

On estimation of improvement with Goodman and Baron's Global qualitative acne scarring system, we found good results in patients with Grades 3 and 4 acne scars. Out of 7 patients with grade 4 scars, $29 \%$ showed improvement by 2 grades and $71 \%$ showed improvement by 1 grade. All the 3 patients with grade 3 scars showed improvement by 1 grade. Boxcar and rolling scars showed better improvement than ice pick scars. On estimation of improvement with Goodman and Baron's Global quantitative acne scarring system, all 10 patients (100\%) showed improvement in their scars with no failure rate. $30 \%$ patients had minimal improvement, 50\% had moderate improvement and $20 \%$ had good improvement with transient side effects such as mild erythema, pain and oedema.

\section{Conclusion}

Subcision and microneedling are simple and inexpensive office procedures which in combination were well tolerated and showed more improvement in boxcar and rolling type atrophic scars as compared to ice pick scars. This minimally invasive multimodality therapy has an added advantage of minimal downtime and can be considered as an effective modality of treatment for moderate to severe acne scars.

2008;59(4):659-676. https://doi.org/10.1016/j. jaad.2008.05.029

5. Fernandes D. Percutaneous collagen induction: an alternative to laser resurfacing. Aesthet Surg J 2002;22:307-309. https://doi.org/10.1067/ maj.2002.126195

6. Fabbrocini G, Fardella N, Monfrecola A, et al. Acne scarring treatment using skin needling. Clin Exp Dermatol 2009;34:874-879. https://doi. org/10.1111/j.1365-2230.2009.03291.x

7. Orentreich DS, Orentreich N. Subcutaneous incisionless (subcision) surgery for the correction of depressed scars and wrinkles. Dermatol Surg 1995;21:543-549. https://doi.org/10.1016/10760512(93)00158-9

8. Goodman GJ, Baron JA. Post acne scarring: A qualitative global scarring grading system. Dermatol Surg 2006;32:1458-66. https://doi. org/10.1111/j.1524-4725.2006.32354.x 
9. Goodman GJ, Baron JA. Postacne scarring: A quantitative global scarring grading system. J Cosmet Dermatol 2006;5:48-52. https://doi. org/10.1111/j.1473-2165.2006.00222.x

10. Fabbrocini G, Annunziata MC, D’Arco V, et al. Acne scars: pathogenesis, classification and treatment. Dermatol Res Pract 2010;2010:893080. https:// doi.org/10.1155/2010/893080

11. Majid I. Microneedling therapy in atrophic facial scars: an objective assessment. J Cutan Asthet Surg 2009;2(1):26-30. https://doi.org/10.4103/09742077.53096

12. Pandey A, Swain J P, Minj A. Assessment of microneedling therapy in the management of atrophic facial acne scars. J Evid Based Med Healthc 2015;2(57):8911-8913. https://doi. org/10.18410/jebmh/2015/1256

13. Varma K, Bhargava S, Kumar U. Microneedling for atrophic post acne scars: Is it effective? A prospective study of 36 patients at tertiary care centre. Hong Kong J Dermatol Venereol 2018;26(2):52-57.

14. Sharad J. Combination of microneedling and glycolic acid peels for the treatment of acne scars in dark skin. J Cosmet Dermatol 2011;10(4):317-323. https://doi.org/10.1111/ j.1473-2165.2011.00583.x

15. Fabbrocini G, De Vita V, Pastore F et al. Combined use of skin needling and platelet-rich plasma in acne scarring treatment. Cosmet Dermatol 2011;24(4):177-183.

16. Asif M, Kanodia S, Singh K. Combined autologous platelet-rich plasma with microneedling verses microneedling with distilled water in the treatment of atrophic acne scars: a concurrent split-face study. J Cosmet Dermatol. 2016;15(4):434-443. https://doi.org/10.1111/jocd.12207

17. Ranjan, S., Gupta, R., \& Gupta, S. A Study of the Efficacy of Skin Needling and Platelet Rich Plasma in the Treatment of Acne Scars. NJDVL 2017; 15(1), 17-23. https://doi.org/10.3126/njdvl.v15i1.18047
18. Rana S, Mendiratta V, Chander R. Efficacy of microneedling with $70 \%$ glycolic acid peel vs microneedling alone in treatment of atrophic acne scars-A randomized controlled trial. J Cosmet Dermatol 2017;16(4):454-459. https:// doi.org/10.1111/jocd.12377

19. Orentreich D, Orentreich N. Subcuteaneous incisionless (subcision) surgery for the correction of depressed scars and wrinkles. Dermatol Surg 1995;21:543-549. https://doi. org/10.1111/j.1524-4725.1995.tb00259.x

20. Alam M, Omura N, Kaminer MS. Subcision for acne scarring: technique and outcomes in 40 patients. Dermatol Surg 2005;31(3):310-317. https://doi. org/10.1097/00042728-200503000-00011

21. Anupama YG, Wahab AJ. Effectiveness of $\mathrm{CO} 2$ laser with subcision in patients with acne scars. J Cosmet Laser Ther 2016;18(7):367-371. https:// doi.org/10.1080/14764172.2016.1188213

22. Faghihi G, Poostiyan N, Asilian A et al. Efficacy of fractionated microneedle radiofrequency with and without adding subcision for the treatment of atrophic facial acne scars: a randomized split-face clinical study. J Cosmet Dermatol 2017;16(2):223229. https://doi.org/10.1111/jocd.12346

23. Bhargava S, Kroumpouzos G, Varma K, Kumar U. Combination therapy using subcision, needling and platelet rich plasma in the management of Grade 4 atrophic acne scars: A pilot study. J Cosmet Dermatol 2019;18(4):1092-1097. https:// doi.org/10.1111/jocd.12935

24. Chandrashekar B, Nandini A. Acne scar subcision. J Cutan Aesthet Surg 2010;3(2):125-126. https:// doi.org/10.4103/0974-2077.63220

25. Bhargava S, Kumar U, Varma K. Subcision and Microneedling as an Inexpensive and Safe Combination to Treat Atrophic Acne Scars in Dark Skin: A Prospective Study of 45 Patients at a Tertiary Care Center. J Clin Aesthet Dermatol 2019;12(8):18-22. 